\title{
Epidemiology and Pathogenesis of Pseudomonas aeruginosa Infections
}

\author{
NICHOLAS M MOORE, MARIBETH L FLAWS
}

\section{Learning Objectives}

Upon reading this article, the reader should be able to:

1. List the infections caused by Pseudomonas aeruginosa.

2. Compare and contrast between infections caused by $P$. aeruginosa in healthy hosts with those in compromised hosts.

3. Discuss the purpose of the National Healthcare Safety Network (NHSN).

4. Summarize the surveillance data reported by the NHSN and its predecessor National Nosocomial Infections Surveillance System (NNIS) with regards to $P$. aeruginosa infections.

5. Explain the mechanisms used by $P$. aeruginosa to evade host defense mechanisms and colonize its host.

INDEX TERMS: Pseudomonas aeruginosa, molecular based methods, anti-microbial resistance.

ABBREVIATIONS: HAI = Healthcare-associated infections, MRSA = methicillin resistant Staphylococcus aureus, NNIS = National Nosocomial Infection Surveillance System, CDC = Centers for Disease Control and Prevention, DSN = Dialysis Surveillance Network, $\mathrm{NaSH}=$ National Surveillance System for Healthcare Workers, NHSN = National Healthcare Safety Network

Clin Lab Sci 2011;24(1):43

Nicholas M. Moore, MS, MLS(ASCP), Rush University, Department of Medical Laboratory Science, Chicago, IL

Maribeth L. Flaws, PhD, SM(ASCP)SI, Rush University, Department of Medical Laboratory Science, Chicago, $I L$
Address for Correspondence: Nicholas M. Moore, MS, MLS (ASCP), Department of Medical Laboratory Science, 600 S. Paulina St., Suite 1014, Chicago, IL 60612, 312942-2111, Fax: (312) 942-6464, Nicholas_Moore@ rush.edu

Pseudomonas aeruginosa is an opportunistic nonfermentive gram negative bacillus that is responsible for a wide variety of infections in humans ranging from relatively uncomplicated urinary tract infections (UTIs) to severe and life threatening infections including neonatal sepsis and chronic lung infections in patients with cystic fibrosis. P. aeruginosa produces a number of membrane bound and secreted virulence factors that aid in the attachment of the organism to host cells, the invasion of tissue, and the inhibition of the immune response.

\section{Epidemiology of $P$. aeruginosa}

It is almost impossible to prevent exposure to $P$. aeruginosa because it can be found anywhere. It is nonfastidious and requires little in terms of nutritional requirements, thus it can be found on inanimate objects such as hospital room sinks, toilets, showers and patient care equipment, especially respiratory ventilators. The surfaces of fresh fruits and vegetables may even harbor $P$. aeruginosa. The organism has a particular predilection for water and as a result, it has been isolated from soaps and disinfectants, contact lens solutions, cosmetics and hot tubs, all of which have been documented as sources of infection. Though not a major member of the human normal flora, it is most commonly found in small amounts in the gastrointestinal tract. It may transiently colonize a variety of moist skin surfaces including under the arm and on the perineum. The throat and nose have been 


\section{FOCUS: PSEUDOMONAS AERUGINOSA}

shown to be sites that may be colonized with $P$. aeruginosa as well. ${ }^{1}$

$P$. aeruginosa can cause infection in almost any part of the body, although it does not typically cause infection in a healthy host. People who are most susceptible to $P$. aeruginosa infections are those whose mucous membranes or skin have become compromised such that they no longer serve as a physical barrier to infection (e.g. in burn patients). Being neutropenic or otherwise immunodeficient predisposes patients to infection with many different organisms of which $P$. aeruginosa is one. The unique lung environment that occurs in patients with cystic fibrosis fosters a chronic infection with $P$. aeruginosa in which the organism displays a characteristic mucoid phenotype due to the production of alginate that surrounds microcolonies of the organism. Hospitalized patients who have cardiovascular disease, cancer or diabetes and especially patients on mechanical respirators are likely to acquire pneumonia or bacteremia due to $P$. aeruginosa. ${ }^{1-3}$ Infections with $P$. aeruginosa in hospitalized patients lead to increased length of stay (LOS) and increased costs as well as significant morbidity and mortality. The type of infection caused by $P$. aeruginosa varies by whether the person is healthy or has underlying disease or had some type of healthcare intervention as summarized in Table 1.

Table 1. Infections caused by $P$. aeruginosa acquired in the community by someone who is healthy vs. in a compromised host with or without healthcare intervention.

\begin{tabular}{|c|c|}
\hline $\begin{array}{l}\text { Community-Acquired by a } \\
\text { Healthy Host }\end{array}$ & $\begin{array}{l}\text { Opportunistic Infections or Health } \\
\text { care Associated Infections (HAI) }\end{array}$ \\
\hline $\begin{array}{l}\text { Otitis externa } \\
\text { (“Swimmer's ear") } \\
\text { Otitis media } \\
\text { Folliculitis ("hot tub } \\
\text { folliculitis") } \\
\text { Keratitis }\end{array}$ & $\begin{array}{l}\text { Bacteremia }^{4} \\
\text { Urinary Tract Infection (UTI) } \\
\text { Meningitis } \\
\text { Pneumonia, including Ventilator } \\
\text { Associated Pneumonia (VAP) } \\
\text { Malignant otitis externa } \\
\text { Burn wound infections }{ }^{10,11}\end{array}$ \\
\hline
\end{tabular}

Healthcare-associated infections (HAI) is the term used for hospital-acquired or nosocomial infections because of the variety of places where patients may undergo treatment and acquire infection. There are an estimated two million HAI in hospitals per year with 90,000 deaths. ${ }^{12}$ In response to the impact HAI have on patient morbidity and mortality, the National Nosocomial Infection Surveillance System (NNIS) was started by the Centers for Disease Control and Prevention (CDC) in the Division of Healthcare Quality Promotion in 1970 and was active until 2004. The NNIS was a system in which participating hospitals with intensive care units (ICUs) voluntarily reported their nosocomial infection surveillance data. In their 1999 report, ${ }^{13} P$. aeruginosa was the second most common cause of nosocomial pneumonia among ICU patients, the fourth most common cause of urinary tract infections (UTIs), and the sixth most common cause of blood stream infections (BSIs). After 1999, the NNIS data summaries reported only the rates of infections with antimicrobial resistant $P$. aeruginosa and will be discussed below.

In 2005, the NNIS, the Dialysis Surveillance Network (DSN) and the National Surveillance System for Healthcare Workers $(\mathrm{NaSH})$ were combined to create the National Healthcare Safety Network (NHSN). ${ }^{14}$ Over 2600 hospitals in the U.S. currently report surveillance data to the NHSN and 21 states mandate that HAI be reported to NHSN as part of patient safety initiatives. Participating facilities are not identified and they can use the aggregated data for inter-facility comparisons and the development of procedures to minimize HAI.

HAI with $P$. aeruginosa are typically attributed to acquiring the organism while in the hospital. While the exogenous spread of the organism from the hospital environment to the patient does occur, there is also endogenous spread of the organism from a site of colonization to a site of pathogenesis. So a colonized patient is not only a risk to others as a source of infection, but also to themselves, something that is not always considered in the prevention of nosocomial infections at least for $P$. aeruginosa. ${ }^{15-18}$ Carriage of methicillin resistant Staphylococcus aureus (MRSA) was recognized a number of years ago as a source of nosocomial MRSA infections. This realization led to the adoption of screening protocols to identify carriers prior to admission and then the treatment of those patients with intranasal mupirocin or other agents. ${ }^{19}$ The 


\section{FOCUS: PSEUDOMONAS AERUGINOSA}

identification and treatment of MRSA carriers resulted in a significant decrease in the rate of post-operative infections due to $S$. aureus. Studies have been performed examining the carriage of $P$. aeruginosa upon hospital admission. These studies found that the children who were studied were not colonized with $P$. aeruginosa, but $6.5 \%$ to $24 \%$ of adults were colonized in the intestinal tract and $9 \%$ in the oropharynx. ${ }^{15-18}$ Perhaps patients who are carriers of $P$. aeruginos $a$ would be at less risk of nosocomial infections if a screening and treatment regimen similar to that used for MRSA were adopted.

An increase in drug-resistant $P$. aeruginosa causing HAI has been observed over at least the last fifteen years. In their 1999 report, the NNIS stated that about $20 \%$ of $P$. aeruginosa isolates were resistant to imipenem, quinolones (ciprofloxacin or ofloxacin) or third generation cephalosporins (ceftriaxone, cefotaxime or ceftazidime), with a significant increase in resistance to imipenem ( $>35 \%)$ and quinolones $(>49 \%)$ as compared to that reported for 1994-1998. ${ }^{13}$ By 2004, 21\% of isolates were resistant to imipenem, $29.5 \%$ were resistant to quinolones and $31.9 \%$ were resistant to third generation cephalosporins. ${ }^{20}$ Not only is $P$. aeruginosa becoming increasingly resistant to one drug, multi-drug resistance is also increasing. The Intensive Care Unit Surveillance Study using data collected from ICUs all over the U.S. as well as another surveillance study performed at a single hospital, both found that multidrug resistance, defined as resistance to $\geq 3$ of the following drugs: ceftazidime, ciprofloxacin, imipenem and tobramycin, increased from about 4\% in 1993 to almost $14 \%$ in $2002 .^{21,22}$ The molecular mechanisms used by $P$. aeruginosa to resist antimicrobial agents will be discussed in the next article. How an organism that is not very virulent can cause significant morbidity and mortality will be discussed next.

\section{Pathogenesis of $P$. aeruginosa}

There are two key elements that contribute to the pathogenesis of $P$. aeruginosa. The first element is the overall health status of the host. As discussed above, hospitalized patients with underlying disease and particularly those who are on a ventilator are most at risk for pneumonia caused by $P$. aeruginosa. The second element contributing to pathogenesis comes from the organism itself. In order for $P$. aeruginosa to cause any type of infection it must first enter the host and colonize. Entry is often via inhalation into the respiratory tract, but the organism is so ubiquitous that is hard to tell exactly how the organism is acquired in all cases. The virulence factors produced by $P$. aeruginosa are listed and summarized in Table 2.23,24 They can be divided into two functional groups: factors that aid in the attachment of the organism to host cells, which are the fimbriae and flagella; and factors that aid in the invasion of tissue and the inhibition of the immune response. All of the virulence factors used by $P$. aeruginosa are also produced by other microorganisms except for pyocyanin which is uniquely produced by $P$. aeruginosa.

Table 2. Virulence factors of $P$. aeruginosa and their function.

\begin{tabular}{|c|c|}
\hline Virulence Factor & Function \\
\hline Fimbriae & $\begin{array}{l}\text { Attachment to host cells and } \\
\text { activation of proinflammatory gene } \\
\text { expression }\end{array}$ \\
\hline Polar flagella & $\begin{array}{l}\text { Motility, attachment to host cells and } \\
\text { activation of Interleukin- } 8\end{array}$ \\
\hline Type III secretion system & $\begin{array}{l}\text { Injects toxins (ExoS, ExoT, ExoU, } \\
\text { ExoY) into host cells }\end{array}$ \\
\hline ExoS & $\begin{array}{l}\text { Stimulates tumor necrosis factor } \\
\text { alpha production }\end{array}$ \\
\hline ExoT & Activates GTPase \\
\hline ExoU & Cytotoxin \\
\hline ExoY & Adenylate cyclase activity \\
\hline Quorum-sensing molecules & $\begin{array}{l}\text { Coordinates expression of genes } \\
\text { among other pseudomonal cells and } \\
\text { promotes the formation of biofilms }\end{array}$ \\
\hline Pyochelin and pyoverdin & Bind iron \\
\hline $\begin{array}{l}\text { Elastase, proteases, } \\
\text { hemolysins, and leukocidin }\end{array}$ & $\begin{array}{l}\text { Aid in tissue invasion and lyse host } \\
\text { cells }\end{array}$ \\
\hline Pyocyanin & $\begin{array}{l}\text { Inhibits lymphocyte proliferation and } \\
\text { cilia function and produces reactive } \\
\text { oxygen intermediates }\end{array}$ \\
\hline Exotoxin A & $\begin{array}{l}\text { Inhibits protein synthesis in host cells } \\
\text { and helps organism disseminate }\end{array}$ \\
\hline Lipopolysaccharide & Endotoxin \\
\hline Alginate & $\begin{array}{l}\text { Free radical scavenger; inhibits } \\
\text { phagocytosis, neutrophil chemotaxis } \\
\text { and activation of complement }\end{array}$ \\
\hline
\end{tabular}

In conclusion, $P$. aeruginosa remains a serious health concern. The organism is ubiquitous in nature, extremely resilient and adaptive to a wide variety of environments. While it is not a major pathogen in an 


\section{FOCUS: PSEUDOMONAS AERUGINOSA}

immunocompetent host, it is a significant cause of HAI in compromised hosts. HAI due to $P$. aeruginosa are decreasing but the percentage of antimicrobial resistant isolates is increasing. $P$. aeruginosa exhibits innate resistance to many antibiotics and can readily develop new resistance mechanisms after exposure to antimicrobial agents. The following sections will discuss specific mechanisms used in antimicrobial resistance and the current therapeutic guidelines to successfully treat infections caused by $P$. aeruginosa.

\section{REFERENCES}

1. Kiska DL, Gilligan PH. Pseudomonas. In: Murray PR, Baron EJ, Jorgensen JH, Pfaller MA, and Yolken RH, editors. Manual of Clinical Microbiology, $8^{\text {th }}$ ed. Washington DC: ASM Press; 2003. p.719-28.

2. Qarah S. Cunha BA, Dua P, Lessnau K-D. Pseudomonas aeruginosa infections. eMedicine accessed 10-28-10 at http://emedicine.medscape.com/article/226748-overview.

3. Chen SP, Rodoy R. Pseudomonas infection. Accessed online at <http://emedicine.medscape.com/article/970904-overview> on October 28, 2010.

4. Weinstein MP, Towns ML, Quartey SM, et al. The clinical significance of positive blood cultures in the 1990s: a prospective comprehensive evaluation of the microbiology, epidemiology, and outcome of bacteremia and fungemia in adults. Clin Infect Dis 1997;24:584-602.

5. Valles J, Mariscal D, Cortes P, et al. Patterns of colonization by Pseudomonas aeruginosa in intubated patients: a 3-year prospective study of 1,607 isolates using pulse-field gel electrophoresis with implications for prevention of ventilatorassociated pneumonia. Intensive Care Med 2004;30:1768-75.

6. Weber DJ, Rutala WA, Sickbert-Bennett EE, et al. Microbiology of ventilator-associated pneumonia compared with that of hospital-acquired pneumonia. Infect Control Hosp Epidemiol 2007;28:825-31.

7. Nseir S, Di Pompeo C, Pronnier P, et al. Nosocomial tracheobronchitis in mechanically ventilated patients: incidence, aetiology and outcome. Eur Respir J 2002;20:14839.

8. Rello J, Ollendorf DA, Oster G, et al. Epidemiology and outcomes of ventilator-associated pneumonia in a large US database. Chest 2002;122:2115-21.

9. Safdar N, Dezfulian C, Collard HR, Saint S. Clinical and economic consequences of ventilator-associated pneumonia: a systematic review. Crit Care Med 2005;33:2184-93.

10. Gang RK, Bang RL, Sanyal SC, et al. Pseudomonas aeruginosa septicemia in burns. Burns 1999;25:611-6.
11. Bjerknes R, Vindenes $H$, Laerum OD. Altered neutrophil functions in patients with large burns. Blood Cells 1990; 16:127-41

12. Weinstein RA. Nosocomial infection update. Emerg Infect Dis 1998;4:416-20.

13. National Nosocomial Infections Surveillance (NNIS) system report: data summary from January 1990-May 1999, issued June 1999. Am J Infect Control 1999;2:520-32.

14. Edwards JR, Peterson KD, Mu Y, et al. National Healthcare Safety Network (NHSN) report: Data summary for 2006 through 2008, issued December 2009. Am J Infect Control 2009;37:783-805.

15. Berthelot P, Grattard F, Mahul P, et al. Prospective study of nosocomial colonization and infection due to Pseudomonas aeruginosa in mechanically ventilated patients. Intensive Care Med 2001;27:503-12.

16. Bonten MJM, Bergmann DCJJ, Speijer H, Stobberingh EE. Characteristics of polyclonal endemicity of Pseudomonas aeruginosa colonization in intensive care units. Am J Respir Crit Care Med 1999;160:1212-9.

17. Agodi A, Barchitta M, Cipresso R, et al. Pseudomonas aeruginosa carriage, colonization, and infection in ICU patients. Intensive Care Med 2007;33:1155-61.

18. Kropec A, Huebner J, Riffel, M, et al. Exogenous or endogenous reservoirs of nosocomial Pseudomonas aeruginosa and Staphy-lococcus aureus infections in a surgical intensive care unit. Intensive Care Med 1993;19:161-5.

19. Van Rijen MM, Bonten M, Wenzel RP, Kluytmans JA. Intranasal mupirocin for reduction of Staphylococcus aureus infections in surgical patients with nasal carriage: a systematic review. J Antimicrob Chemother. 2008;61:254-61.

20. National Nosocomial Infections Surveillance (NNIS) system report, data summary from January 1992 through June 2004, issued October 2004. Am J Infect Control 2004;32:470-85.

21. Obritsch MD, Fish DN, MacLaren R, Jung R. National surveillance of antimicrobial resistance in Pseudomonas aeruginosa isolates obtained from intensive care unit patients from 1993 to 2002. Antimicrob Agents Chemother 2004;48:4606-10.

22. D'Agata, EM. Rapidly rising prevalence of nosocomial multidrug-resistant, gram negative bacilli: a 9-year surveillance study. Infect Control Hosp Epidemiol 2004;25:842-6.

23. Sadikot RT, Blackwell TS, Christman JW, Prince AS. Pathogen-host interactions in Pseudomonas aeruginosa pneumonia. Am J Respir Crit Care Med 2005;171:1209-23.

24. Driscoll JA, Brody SL, and Kollef MH. The epidemiology, pathogenesis and treatment of Pseudomonas aeruginosa infections. Drugs 2007;67:351-68. 